\title{
EXPERIMENTAL RESEARCH OF THE POWER SUPPLY SOURCE PARAMETERS USED IN PROXIMITY SENSORS FOR ARTILLERY PROJECTILES
}

\author{
S. Grzywiński", S. Żygadło**
}

\begin{abstract}
One of the most important components of the radio proximity sensor is its power source. Depending on the purpose of the sensor, various types of power supply are used. The paper presents a description of the measurement stand and tests the results of power source used to power radio proximity sensors in artillery projectiles.
\end{abstract}

Keywords: radio proximity sensor, backup battery

\section{Introduction}

One of the effective methods of increasing the effectiveness of fragmentation is equipping artillery projectiles with radio proximity sensors. Their use in place of impact or time sensors increases from 2 to 15 times the effectiveness of the fragmentation of ground targets, when the projectile-triggered explosions initiated by the sensor take place in a well-defined range above the ground. The radio sensor measures the height of the projectile above the ground and generates a signal when the measured altitude corresponds to the required one. It can be a Doppler, pulse, frequency or combination sensor, whereas Doppler sensors are commonly used in proximity sensors in artillery projectiles. This is due to the fact that this type of sensor is characterized by simple construction, small dimensions, high reliability in operation and low unit cost, which in the case of artillery projectile mass of the sensor is of great importance. Reliable operation of the proximity sensor depends on the operating conditions related to the internal and external ballistics of the projectiles and on the parameters of the used electronic. According to the applicable shooting tables, it can be estimated that the range of changes in the value of factors determining working conditions of a proximity sensor for artillery projectiles is (Żygadło, 2016):

- total range $(4000 \div 20000) \mathrm{m}$;

- total flight time of projectiles $(5 \div 95) \mathrm{s}$;

- linear acceleration of the projectiles at the shooting moment $(32500 \div 165000) \mathrm{m} / \mathrm{s}^{2}$;

- angular velocity $(18500 \div 45000) \mathrm{rad} / \mathrm{s}$;

- final speed of the projectiles $(200 \div 400) \mathrm{m} / \mathrm{s}$;

- fall angle of projectiles $(10 \div 75)^{\circ}$.

Defense standards impose that the used components should allow to obtain a radio proximity sensor that will be completely resistant to (MON, 2005):

- $\quad$ sinusoidal vibrations (occurring on the flight path of the projectile) with an amplitude of $100 \mathrm{~m} / \mathrm{s}^{2}$ and frequency in the interval $(1 \div 2000) \mathrm{Hz}$;

- single mechanical impacts (occurring in the barrel) with peak acceleration not exceeding $165000 \mathrm{~m} / \mathrm{s}^{2}$

Stanisław Grzywiński, PhD,: Faculty of Mechatronics \& Aerospace, Military Uniwersity of Technology, Urbanowicza 2, 00-908 Warsaw, PL, stanislaw.grzywinski@wat.edu.pl

** Stanisław Żygadło, PhD,: Faculty of Mechatronics \& Aerospace, Military Uniwersity of Technology, Urbanowicza 2, 00908 Warsaw, PL, stanislaw.zygadlo@wat.edu.pl 
- fall from a height of at least $1.5 \mathrm{~m}$ (including a projectile);

- changes in ambient temperature from $<-32{ }^{\circ} \mathrm{C} ;+50>{ }^{\circ} \mathrm{C}$ and single-mechanical impacts $165000 \mathrm{~m} / \mathrm{s}^{2}$.

One of the most important components of the radio proximity sensor is its power source. Different types of power supplies are used for these sensors, but the most extensive use has been found in Multi stack reserve Li-SOCl2 batteries. Under operating conditions (storage, transport and combat use), the battery's task is to:

- self-activate to specified voltage $(12 \pm 2 \mathrm{~V})$ in a very short time, after firing a projectile;

- provide a stable current of $250 \mathrm{~mA}$ for a minimum duration of $200 \mathrm{~s}$;

- fulfil these functions after storage period of not less than 10 years.

After analysing the market, a reserve battery UA6215 from THALES CRYOGENICS was selected for tests (Fig. 1) (Thales, 2018). Spare battery structure is based on a lithium-thionyl chlorine compound (LiSOCI2), which ensures high energy density. The electrodes are made of carbon and the electrolyte is stored in a glass ampoule suspended in a special construction.

a)

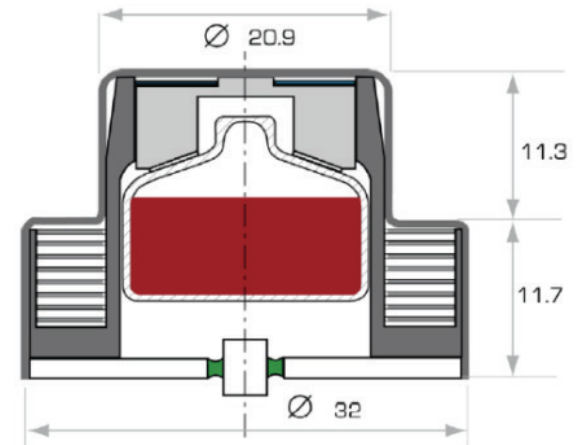

b)

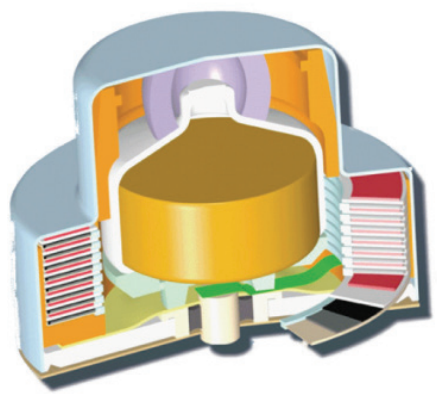

Fig. 1: Backup battery UA6215 (Thales, 2018)

a) technical drawing, b) cross-sectional drawing

The basic parameters and characteristics of the UA6215 battery are (Thales, 2018):

- $\quad$ supply voltage $(3,5 \div 31,5) \mathrm{V}$ in steps of $3.5 \mathrm{~V}$ per cell;

- current $250 \mathrm{~mA}$ by the time $\geq 200 \mathrm{~s}$;

- activation time $\leq 40 \mathrm{~ms}$;

- activation is forced by acceleration $15000 \mathrm{~m} / \mathrm{s}^{2}$ and angular speed $2900 \mathrm{rpm}$;

- ambient temperature $<-46 ;+63>{ }^{\circ} \mathrm{C}$;

- impact resistance of $500000 \mathrm{~m} / \mathrm{s}^{2}$ and angular speed of $30000 \mathrm{rpm}$;

- storage period of 20 years.

According to the above characteristics, the activation of the UA6215 battery should force linear acceleration of not less than $15000 \mathrm{~m} / \mathrm{s}^{2}$ and rotation of the projectile with an angular speed of at least $2900 \mathrm{rpm}$. This battery should be durable and resistant to impacts not exceeding $165000 \mathrm{~m} / \mathrm{s}^{2}$, angular speeds $19200 \mathrm{rpm}$ and the temperature of $<-32{ }^{\circ} \mathrm{C}:+50>{ }^{\circ} \mathrm{C}$.

\section{Stand for testing the parameters of the power source}

The tests were carried out on UA6215 batteries placed in the ZZbA-10 proximity sensor housing for artillery projectiles. The quality tests of the battery activation process were carried out on the measurement stand shown in Fig. 2 (Żygadło, 2016, Baranowski et al., 2017).

The research of the activation process were carried out under various temperature conditions. It was checked whether after impact surge of $4000 \mathrm{~m} / \mathrm{s}^{2}$ the batteries will not be and after impact surge greater than $20000 \mathrm{~m} / \mathrm{s}^{2}$ will be activated (in condition of max delay: $40 \div 50 \mathrm{~ms}$ ) to the voltage from the range $(9 \div 14) \mathrm{V}$. In the proper conditions the $250 \mathrm{~mA}$ current should flow for $200 \mathrm{~ms}$ through resistor $\mathrm{R}_{\mathrm{ob}}=50 \Omega$ and then, battery should fuse the electric plug EW -32 within no more than $(3 \div 5)$ ms delay. 


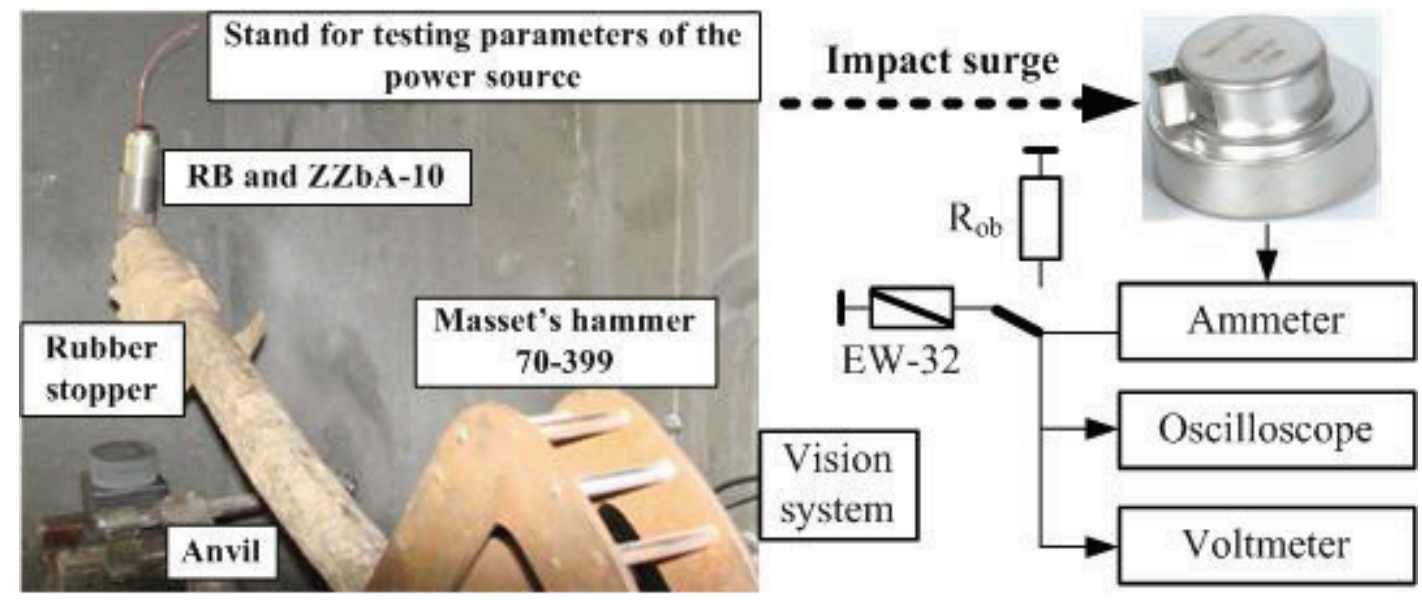

Fig. 2: Stand for testing the parameters of the power source (Żygadto, 2016; Baranowski et al., 2017)

For testing at a normal temperature of $+23{ }^{\circ} \mathrm{C}$ the battery was placed in the ZZb-A10 sensor housing, which was then attached to the Masset's hammer arm. A rubber plug with a hardness of $40^{\circ} \mathrm{Sh}$ was placed on the hammer's anvil and the hammer arm was clamped on the 20th tooth giving impact surge of approx. $40000 \mathrm{~m} / \mathrm{s}^{2}$. After starting the registration and releasing Masset's arm, a signal was observed on the screen of the and measuring instruments. The voltage level was zero, which means that the battery was not activated.

Then a rubber plug with a hardness of $90^{\circ} \mathrm{Sh}$ was placed on the anvil, and the Masset's hammer arm was blocked on the 23th tooth, giving a shock with an acceleration of about $210000 \mathrm{~m} / \mathrm{s}^{2}$. After starting registration and releasing the Masset's hammer arm, the battery activation voltage appeared on the oscilloscope screen (Fig. 3). The non-centrifuged battery was activated to a voltage of approx. $13 \mathrm{~V}$ after a time of approx. $20 \mathrm{~ms}$. Under a load of $50 \Omega$ and after about $180 \mathrm{~s}$ the voltage dropped to about $11 \mathrm{~V}$. After attaching the resistor $10 \Omega$ the battery voltage was reduced to approx. $5 \mathrm{~V}$ (after removing this load it increased to approx. $12 \mathrm{~V}$ ). After connecting the EW-32 electric primer to the battery in less than $2 \mathrm{~ms}$ it was ignited.

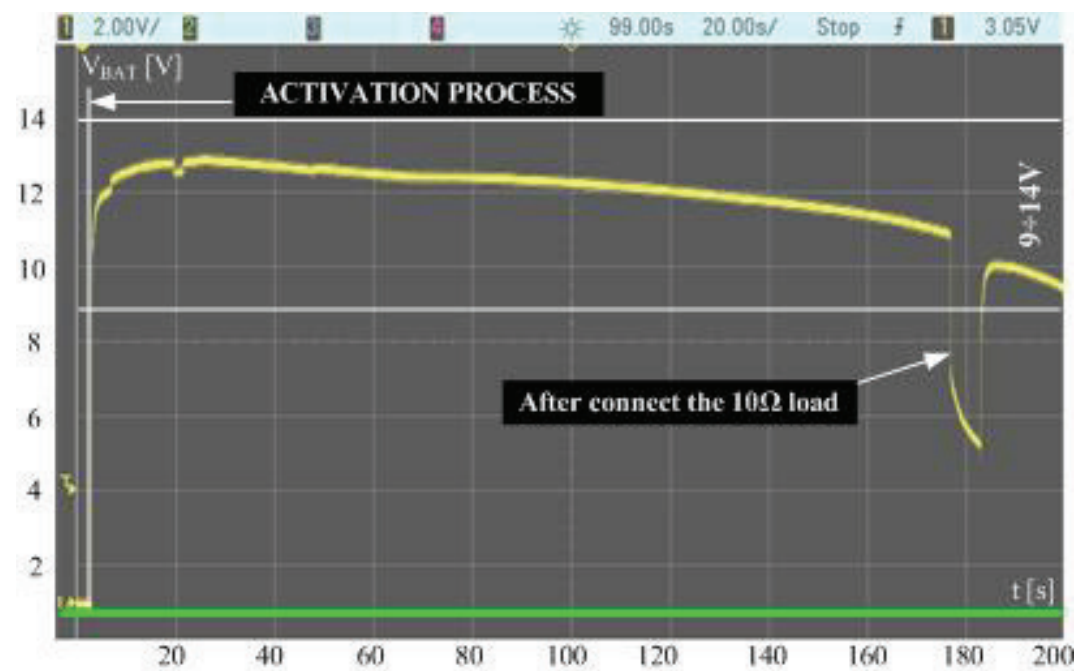

Fig. 3: The battery voltage after impact surge approx. $210000 \mathrm{~m} / \mathrm{s}^{2}$ (without centrifugation) at temperature $+23{ }^{\circ} \mathrm{C}$

The battery shock resistance test was performed after holding it for $2 \mathrm{~h}$ at an elevated temperature of $+50{ }^{\circ} \mathrm{C}$ and then at a reduced temperature of $-32{ }^{\circ} \mathrm{C}$. Masset's hammer arm was locked on 23th tooth, giving impact surge of about $210000 \mathrm{~m} / \mathrm{s}^{2}$. In both cases, after starting the registration and releasing the Masset's hammer arm, the battery activation voltage appeared on the oscilloscope screen (Fig. 4 and Fig. 5). The non-centrifuged battery was activated to a voltage of approx. $12.5 \mathrm{~V}$ after a time of approx. $15 \mathrm{~ms}$. Under the load of $50 \Omega$ and after about $180 \mathrm{~s}$ the voltage dropped to about $11 \mathrm{~V}$. After this time an EW-32 electric primer was connected to the battery, which caused it to fuse with a delay less than $2 \mathrm{~ms}$. 


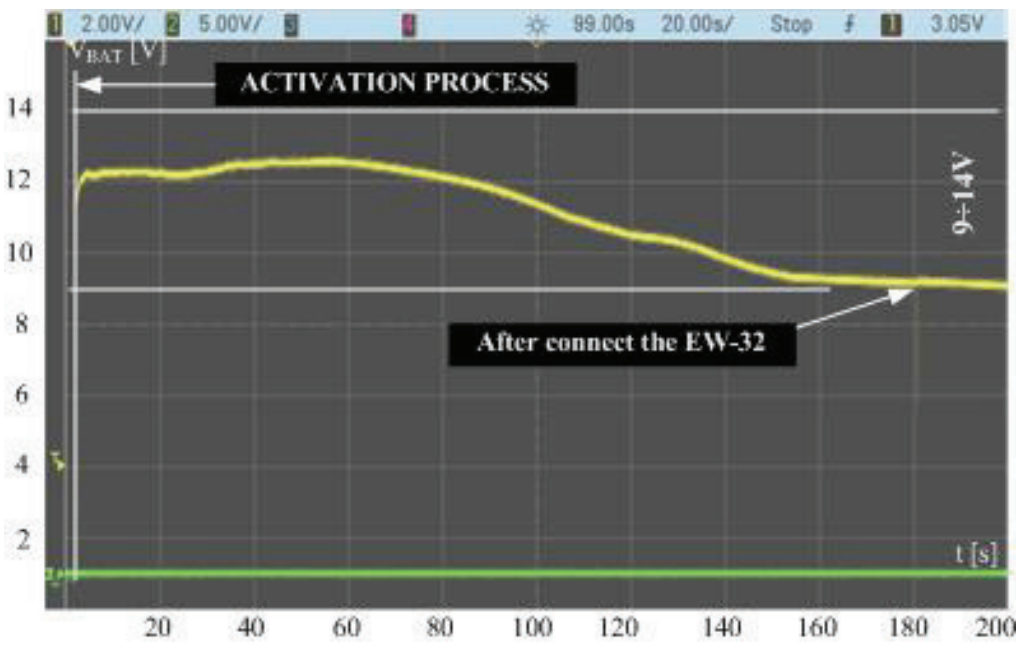

Fig. 4: The battery voltage after impact surge approx. $210000 \mathrm{~m} / \mathrm{s}^{2}$ (without centrifugation) at temperature $+50{ }^{\circ} \mathrm{C}$

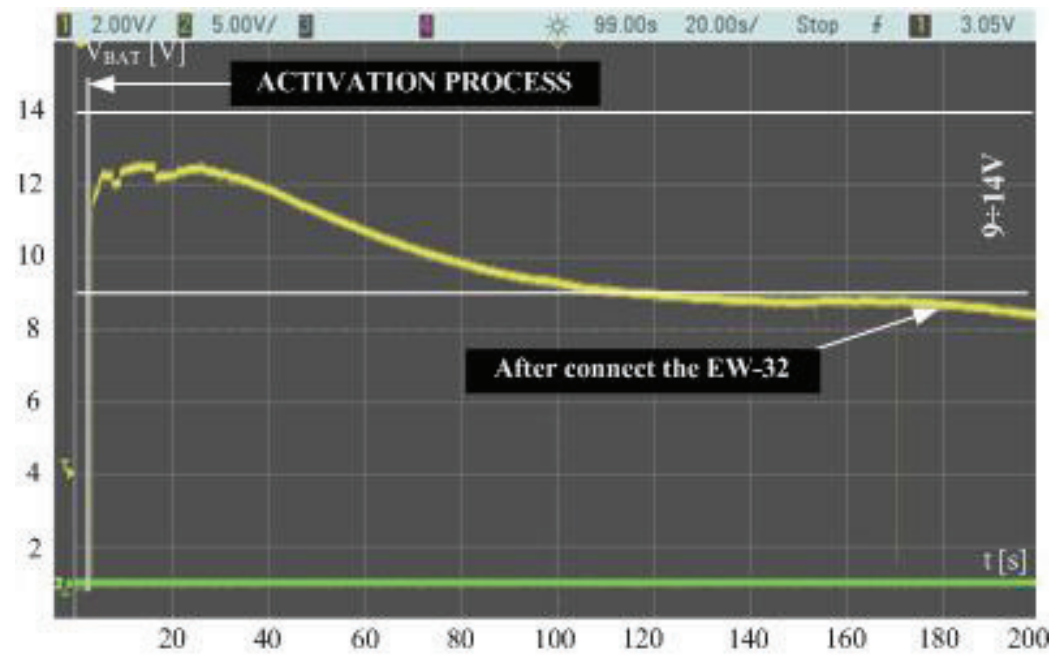

Fig. 5: The battery voltage after impact surge approx. $210000 \mathrm{~m} / \mathrm{s}^{2}$ (without centrifugation) at temperature $-32{ }^{\circ} \mathrm{C}$

\section{Conclusions}

Based on the results of the UA6215 multi stack reserve batteries tests, it can be concluded that:

- described measuring stand enables precise measurement and registration of the battery activation process as a function of linear accelerations obtained on the Masset's hammer and in various temperature conditions;

- all tests ended with a positive result, and the recorded voltage waveforms testify high functional values of the tested batteries;

- tests were carried out without centrifugation. Centrifuging, which occurs at the moment of the shot, will improve the conditions of battery activation and will minimize the possibility of momentary short-circuits at its terminals;

- The UA6215 backup battery can be successfully used as a power source for the proximity sensor.

\section{References}

Baranowski, L., Kaczmarek, W., Panasiuk, J., Prusaczyk, P. and Besseghieur, K.I. (2017) Integration of vision system and robotic arm under ROS, In: Engineering Mechanics 2017, Brno University of Technology, Brno, pp. 114-117.

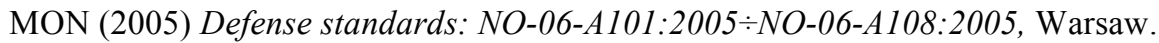

Thales (2018) http://www.thales-cryogenics.com/product-category/batteries/lisocl2/.

Żygadło S. (2016) Proximity fuses for artillery and rocket ammunition, WAT, Warsaw. 